\title{
A Química na Reforma Curricular dos Ensinos Básico e Secundário
}

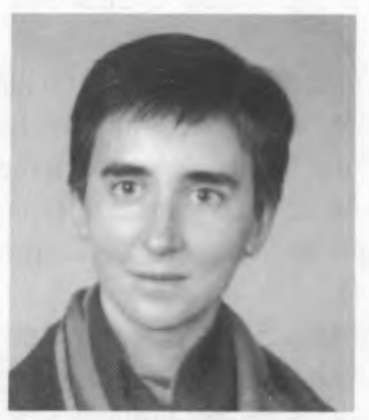

Maria Clara Magalhães

Licenciou-se em Química pela Faculdade de Ciências da Universidade de Lisboa em 1978.

Doutorou-se em Química, especialidade Química Inorgânica, na Universidade de Aveiro em 1989.

Realizou um pós-doutoramento em Química Bioinorgância no Departamento de Química da Universidade de Basileia, Suiça (1989-1990).

Foi Professora Provisória do 4. grupo A na Escola Industrial e Comercial Alfredo da Silva, Barreiro (1972-1976), e na Escola Técnica de Anselmo de Andrade, Almada (1976-1977) onde realizou o estágio pedagógico.

Foi Professora Agregada do 4. . grupo A na Escola Industrial Machado de Castro, Lisboa (1977-1979).

Na Universidade de Aveiro foi Assistente Estagiária (1979-1981) e Assistente (1981-1989) sendo Professora Auxiliar desde 1989.

É responsável pelo projecto de investigação sobre «Síntese e caracterização estrutural e termodinâmica de soluções sólidas».

É coordenadora da Prática Pedagógica das Licenciaturas em Ensino.
A elaboração de um programa não é um trabalho nada fácil, mas torna-se ainda mais difícil aos níveis introdutórios ensinos básico e secundário. Comentar uma proposta de ensino é uma tarefa bastante mais simplificada!

Qualquer programa de ensino envolve uma metodologia. E qualquer método tenderá para ser um processo em evolução contínua, e deve querer-se sujeito a uma crítica no sentido do seu aperfeiçoamento. É nesta perspectiva que apresento uma reflexão sobre os programas de química propostos para a reforma curricular iniciada em 1990. Esta reflexão divide-se em duas partes: uma apreciação global, e comentários sobre questões específicas dos conteúdos. Não se pretende um estudo exaustivo mas somente uma abordagem das matérias que mais interrogações levantaram no modo como estão expostas.

\section{Apreciação global}

Para que um projecto se apresente como um todo coerente é necessário haver um corpo estruturado de conceitos que rejam a globalidade do processo de ensino-aprendizagem. Na disciplina de Física e Química estes encontram-se explicitados em 1-Introdução, 2-Finalidades Formativas e 3 Objectivos Gerais da Disciplina, da Proposta do Programa de Físico-Químicas para o $3 .^{\circ}$ Ciclo do Ensino Básico (8. ${ }^{\circ} \mathrm{e}$ 9. ${ }^{\circ}$ anos) sendo extensivos também ao Ensino Secundário. Se alguns dos objectivos são específicos da disciplina de Física e Química, outros há que devem fundamentar qualquer percurso de ensino-aprendizagem, não cabendo a sua apreciação no âmbito desta análise.

De uma maneira geral os conteúdos programáticos agora apresentados, para a componente de Química, não diferem muito dos programas actualmente em vigor. A grande mudança reside na metodologia proposta para o estudo das diversas Unidades de Ensino:

- abordagem numa perspectiva essencialmente experimental;

- articulação do ensino da Física e da Química entre si e com outros domínios do saber;

- conexão entre a Química e o desenvolvimento científico, tecnológico e social.

Estes aspectos inovadores irão exigir grandes alterações tanto ao nível das disponibilidades físicas e materiais da escola como das mentalidades, para não falar da própria formação de professores. 
Algumas das aulas deverão ser leccionadas no laboratório, que necessitará estar minimamente equipado e contar com a colaboração indispensável de um técnico auxiliar experiente. Tendo em consideração a realidade portuguesa, em que muitas escolas não possuem espaços físicos disponíveis para funcionarem como laboratórios a tempo inteiro, e não existe o técnico auxiliar considerado indispensável, como se poderá introduzir a nova metodologia de ensino da Química? Trocar o laboratório por toda uma gama de recursos educacionais não torna esta disciplina mais atractiva, retira-lhe o que ela poderá ter de cativante - a experimentação. Transparências, diapositivos, filmes, microcomputadores, etc. são meios auxiliares de ensino e não substitutos do laboratório. A realização de pequenas experiências pelos alunos permitelhes tomarem contacto com uma das vertentes de uma ciência teórico-experimental.

Uma análise breve das propostas divulgadas dos programas de Física dos $8 .^{\circ}$ ao $11 .^{\circ}$ anos mostra uma falta considerável de ligação entre os programas de Física e Química que constituem a mesma disciplina. É desejável que a reformulação exigida presentemente para os programas de Física possa diminuir esta divergência. Como se pretenderá efectuar a ligação da Química com outras áreas do saber, como as ciências da terra e da vida, tradicional e academicamente desligadas da Química? Como ligar a Química ao desenvolvimento social, avanços tecnológicos e problemas ambientais?

Uma parte interessante desta disciplina dependerá também de uma boa escolha de aplicações científicas e tecnológicas modernas. Nestes aspectos reside um grande desafio aos autores dos futuros manuais escolares, já que na ausência de programas adequados de formação contínua de professores, estes ficam «dependentes» da bibliografia publicada.

O ensino da Química de acordo com os novos programas exige dos professores um leque alargado de conhecimentos. Requer também da parte dos alunos a consulta de fontes variadas de informação (enciclopédias, jornais, livros, revista, etc.) que devem ser seleccionadas de acordo com a sua qualidade científico-pedagógica. As bibliotecas (escolares e municipais) estão, regra geral, deficientemente apetrechadas com livros técnicos e de divulgação científica. O professor anónimo de Física e Química ou não tem conhecimento ou tem um conhecimento deficiente da bibliografia mais especializada. Assim, parece-me uma lacuna grave a ausência de referências bibliográficas. Onde irão os professores procurar os necessários complementos de formação?

\section{Análise de conteúdo}

Um estudo pormenorizado dos programas propostos para aplicação em regime experimental evidenciou diversas inconsistências linguísticas que podem induzir ambiguidades no desenvolvimento de Unidades Didácticas e explicação de conceitos. A utilização menos correcta da linguagem identifica-se quer ao nível da estrutura quer do conteúdo. Neste contexto considero essencial alguns comentários sobre grandezas físicas e unidades, e critérios para interpretar e prever a extensão das reacções. Além deste temas apresentam-se alguns exemplos pontuais que pretendem demonstrar a necessidade de um exame crítico dos novos programas.
A substituição em todos os programas da palavra «quantidade» por «porção» na grandeza quantidade de substância não me parece a mais conveniente. Os significados vulgares [1] de porção e quantidade * tornam esta última palavra mais adequada para exprimir uma grandeza física. De acordo com as últimas recomendações da IUPAC [2] a palavra «substância» pode ser substituída pelo nome da respectiva substância. Por exemplo, em vez de «quantidade de substância de oxigénio» pode dizer-se «quantidade de oxigénio». No entanto, ao nível introdutório, creio que esta simplificação poderá trazer dificuldades aos alunos. Note-se ainda que, no caso do oxigénio e de outros equivalentes, é necessário tornar claro se se está a mencionar o elemento ou a substância elementar.

Também não se compreende que a constante de Avogadro seja designada no 9. 9 ano como «número de Avogadro» e que ao nível do $12 .^{\circ}$ ano se chame correctamente constante de Avogadro. Trata-se de uma grandeza física com dimensões de inverso de quantidade de substância $\left(\right.$ mole $\left.^{-1}\right)$ e não de um número puro [2-4].

Denominar a Unidade 5, do programa de Ciências FísicoQuímicas do $10 .^{\circ}$ ano, de Quantidade em Química não me parece muito correcto. Nesta Unidade de Ensino estudam-se as grandezas físicas - quantidade de substâncias, massa molar, volume molar e concentração. Será que denominar Quantidade em Química uma Unidade de Ensino onde se referem outras grandezas físicas e métodos de determinação analítica, não causará grande perturbação no ensino de uma grandeza física que devido à sua novidade ainda não entrou no quotidiano de muitos professores? Porque não denominála, por exemplo «Grandezas e Unidades em Química. Cálculos estequiométricos»? Nas últimas recomendações da IUPAC [2] refere-se que a quantidade de substância tem sido usada pelos químicos há muito tempo sem um nome próprio. Era referida simplesmente como «número de moles». Esta prática deverá ser abandonada porque está errado confundir o nome da grandeza física com o nome da unidade.

Nesta Unidade Didáctica, o objectivo específico: Realizar cálculos sobre concentração de soluçōes expressa em massa por unidade de volume de soluçāo e em mole de soluto por $\mathrm{dm}^{3}$ de solução (molaridade), induz as seguintes observações:

- a substituição da palavra molaridade por concentração já foi proposta pela IUPAC [4] em 1971, para evitar a confusão com molalidade, e para que a palavra «molar» que significa "por unidade de quantidade de substância» ou em alguns casos «unidade de concentração» não seja utilizada para a unidade de concentração - mole de soluto por $\mathrm{dm}^{3}$ de solução;

- a concentração é uma grandeza física relacionada com a composição de soluções. A sua unidade SI é a mol $\mathrm{m}^{-3}$ podendo utilizar-se múltiplos e submúltiplos desta unidade. Outra grandeza que traduz a composição das soluções é a concentração mássica (massa de soluto por unidade de vo-

\footnotetext{
* Porção - parte de um todo; fracção; parcela; certa quantidade de qualquer coisa; bocado; fragmento; quinhão. Quantidade - qualidade do que pode ser medido ou numerado; qualidade do que é susceptível de aumento ou diminuição; grande número; valor das vogais ou das sílabas; tempo que se emprega em pronunciá-las; duração relativa dos sons musicais.
} 
lume da solução) [3]. Se cada grandeza física (com dimensões) tem associada uma unidade porquê a necessidade de referir as unidades de concentração e de concentração mássica? Não é correcto utilizar a concentração como sinónimo de composição. Esta confusão é bastante geral. Por exemplo, nas sugestões metodológicas para o ensino da Unidade 12 do 8. ${ }^{\circ}$ ano afirma-se: $O$ professor deverá integrar o uso de modos simples de exprimir concentrações, designadamente em grama por $\mathrm{dm}^{3}$....

Do exposto pode concluir-se que os diagramas de fluxos de conceitos, Materiais: constituição e transformaçôes (8. $e 9 .^{\circ}$ anos) do programa do $3 .^{\circ}$ ciclo do Ensino Básico e Quantidade em Química apresentado no programa do $10 .^{\circ}$ e $11 .^{\circ}$ anos do Ensino Secundário, devem ser alterados. A quantidade de substância é uma grandeza física que tem uma definição e um objecto de aplicação. Da forma como o organograma, apresentado no programa dos $10 .^{\circ} \mathrm{e} 11 .^{\circ}$ anos, está representado pode inferir-se que a quantidade de substância é uma grandeza relacionada com a massa e o volume. Nas Figuras 1 e 2 representam-se as alterações propostas aos fluxos de conceitos referidos.

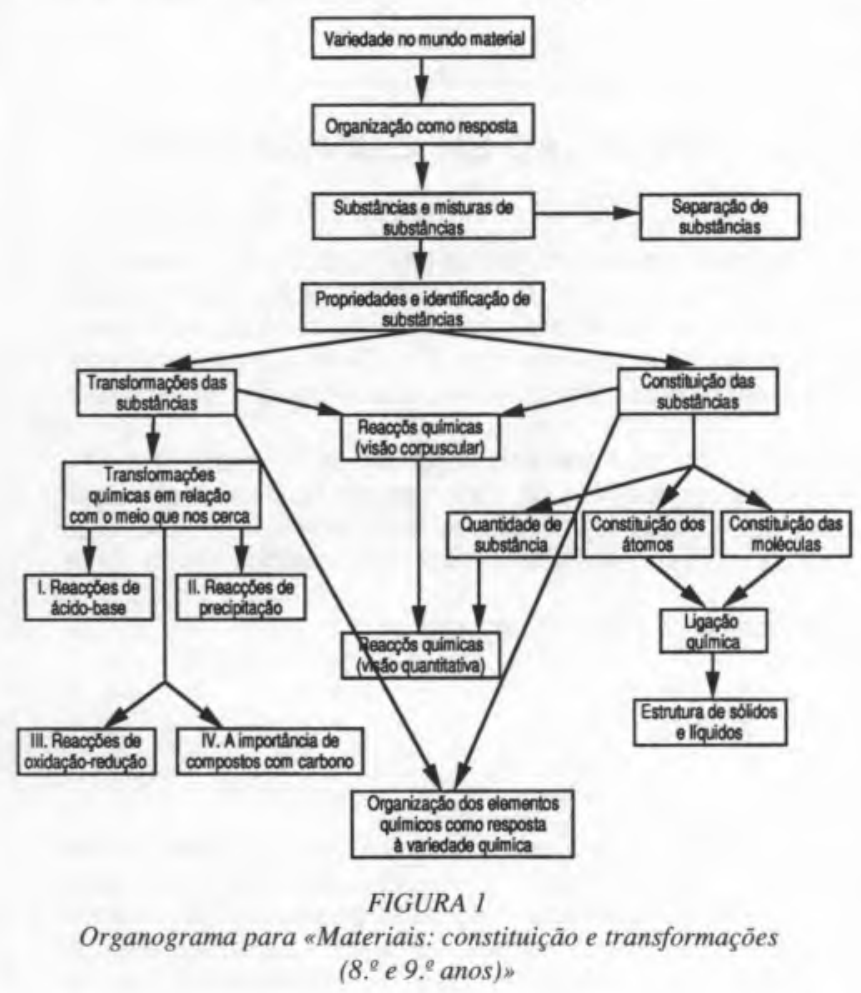

Ainda no programa do $10 .^{\circ}$ ano mas na Unidade 7 onde se indica ...uma classificaçâo em sais solúveis, pouco solúveis $e$ insolúveis deve dizer-se «... uma classificação em sais solúveis e pouco solúveis». Do ponto de vista experimental não existem substâncias insolúveis.

Na Unidade 1 do programa do $12 .{ }^{\circ}$ ano em vez de Discutiro efeito da temperatura do oxigénio na solubilidade deste gás na água, deve escrever-se «Discutir o efeito da temperatura na solubilidade do oxigénio na água». O modo como está redigido pode parecer que a temperatura do gás e da água são duas grandezas distintas.

Apresentar nos programas do $11 .^{\circ} \mathrm{e} 12 .^{\circ}$ anos a entropia como «balbúrdia corpuscular» ou «caos» microscópico não será uma atitude demasiado redutora?

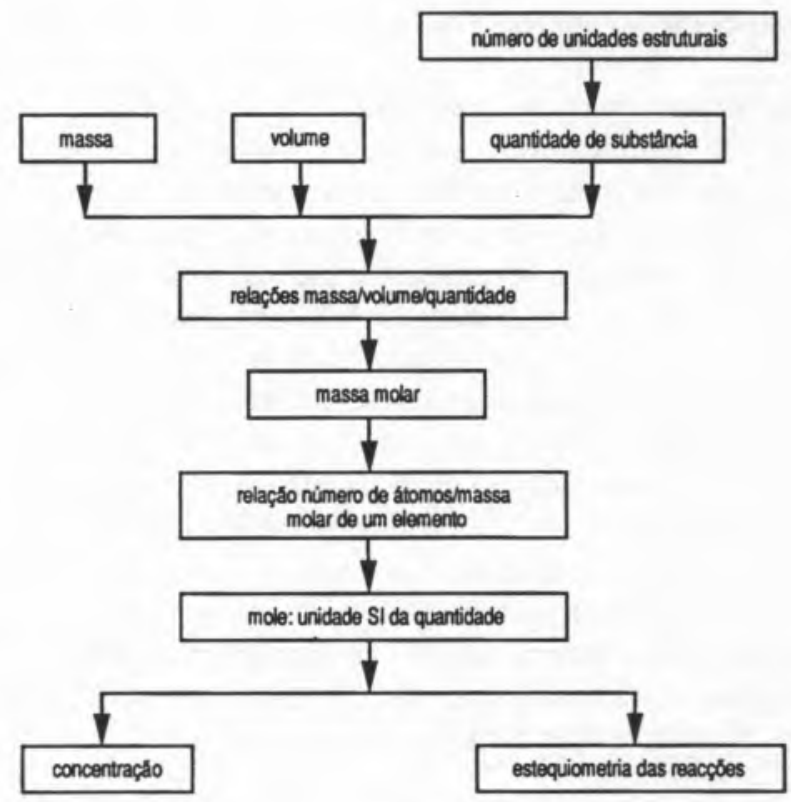

FIGURA 2

Proposta de organograma para «Grandezas físicas e unidades»

O estudo da entropia e não da energia de Gibbs - facto salientado pelos autores que lhe chama energia livre [5] - é explicado nas sugestões metodológicas pela ligação que se pretende com o ensino da Física. Será esta função termodinâmica a que melhor se aplica ao estudo das reacções químicas? No meio que nos rodeia ocorrem continuamente reacções químicas. É a vida no ecossistema terra. Sendo a terra um reservatório de pressão e temperatura porque não utilizar a energia de Gibbs? Que reacções se podem prever com base na variação de entropia? Porquê utilizar como critério de espontaneidade um conceito que me parece de aplicação demasiado restrita, e em situações académicas? Sendo o programa de Química bastante extenso e prevendo-se para a Unidade 6 do 11..$^{\circ}$ ano unicamente três aulas (o que será insuficiente para uma aprendizagem dos conceitos que se querem introduzir) porque não retirar esta Unidade de Ensino do programa referido? A sua supressão não introduzirá lacunas nos conhecimentos dos alunos que poderão estudar os critérios para interpretar e prever reacções ao nível do 12. ${ }^{\circ}$ ano.

Os aspectos bastante positivos dos novos programas são a introdução ao nível do 9.9 ano da Unidade 8 -A Química e $O$ seu impacto na sociedade e ao nível do $12 .^{\circ}$ ano da parte II $-A$ Química, uma ciência em acção. Se para o $12 .{ }^{\circ}$ ano esta parte II corresponde a cerca de $40 \%$ do programa para o 9. 9 ano são referidas apenas duas horas para a sua realização. Pretendendo-se que os alunos saiam do ensino básico com uma formação global que lhes permita interpretar os fenómenos do dia a dia, conhecer melhor o mundo em que vivem e inserir-se bem na sociedade do presente e do futuro... e insuficiente reduzir a Unidade 8 a uma recolha retrospectiva de exemlos já estudados e organizá-los em temas.

É no desenvolvimento destas Unidades de Ensino que tanto os alunos como os professores terão de recorrer a outra bibliografia que não os manuais escolares, pelo menos os de tipo actual. Torna-se assim mais saliente a grande lacuna que os programas apresentam a este nível. 


\section{Sugestōes metodológicas finais}

Se se pretende uma maior interligação entre o meio que nos rodeia e a Química creio que os processos de oxidação/ /redução são os mais estimulantes para essa acção [6]. Os alunos estão familiarizados com fenómenos como a combustão, a fotossíntese, a respiração, e outros - muitos dos exemplos utilizados na Unidade 13 do $8{ }^{\circ}{ }^{\circ}$ ano são de reacções deste tipo (corrosão, electrólise, reacções fotoquímicas). Porque não aproveitar estes conhecimentos para de uma forma elementar introduzir conceitos de Química? Será também uma boa ocasião para os alunos perceberem a importância da estrutura electrónica, que é ensinada, em geral, de uma maneira muito académica.

Como balanço final gostaria de referir que uma execução cabal dos novos programas de Química exigirá além das mudanças institucionais, uma alteração profunda na formação de professores tanto inicial como contínua.
Referências

[1] Lexilello, Novo Dicionário de Língua Portuguesa, Lelloe Irmão Editores, Porto, 1989.

[2] IUPAC, Physical Chemistry Division, Quantities, Units and Symbols in Physical Chemistry, Blackwell Scientific Publications, Oxford, 1988.

[3] M.E. Jardim, M.E. Pereira, Terminologia, Símbolos e Unidades para Grandezas Físico-Químicas, Escolar Editora, Lisboa, 1985.

[4] M.L. McGlashan, Physico-Chemical Quantities and Units, 2nd ed., Monographs for Teachers No 15, The Royal Institute of Chemistry, London, 1971.

[5] IUPAC, Physical Chemistry Division, Manual of Symbols and Terminology for Physicochemical Quantities and Units, Appendix IV - Notation for States and Processes, Significance of the Word «Standard $»$ in Chemical Thermodynamics, and Remarks on Commonly Tabulated Forms fo Thermodynamic Functions, Pure Appl. Chem., 1982, 54, 1239-1250.

[6] M.C.F. Magalhães, Oxidação/redução: uma perspectiva de ensino com base em sistemas naturais, Actas do $2 .^{2}$ Encontro Nacional de Didácticas e Metodologias de Ensino, Universidade de Aveiro, 1991, 589-600.

\section{Agradecimentos}

Agradeço aos Doutores Ana Luísa Janeira, José Estrela e Maria Isabel Martins pelos comentários e sugestões que me foram facultando ao longo do trabalho.

\section{1. " CONFERÊNCIA INTERNACIONAL DE EDUCAÇÃO EM QUÍMICA (ICCE)}

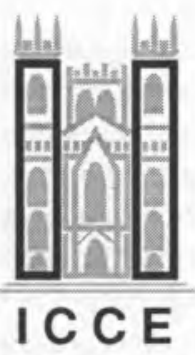

\section{York 25 a 30 de Agosto de 1991}

Não é a primeira vez que aparece no Boletim da SPQuma notícia sobre as Conferências Internàcionais de Educação em Química (1, 2), organizadas pelo Comité para o Ensino da Química (CEQ) da IUPAC, sob os auspícios da Unesco, que se realizam aproximadamente de dois em dois anos. Em Setembro de 1989 a Conferência decorreu em Waterloo, Canadá, e as próximas realizar-se-ão em Dezembro de 1992 em Bangkok e em 1994 em Porto Rico. Constituem um forum para professores interessados em Educação em Química exporem e compartilharem ideias e projectos de investigação e desenvolvimento.

A 11. Conferência teve por tema "Bringing chemistry to life». Foi presidida pelos Professores D. Waddington e M. Chastrette, ambos já conhecidos de muitos professores portugueses envolvidos em questōes de Educação em Química. Houve uma participaçâo massiça de 650 participantes de 64 países; a maioria dos participantes ficou alojada no campus da Universidade de York, o que fomentou reuniōes e conversas informais que abriram ou cimentaram trabalhos de interesse comum, envolvendo participantes de vários países.

No Programa das conferências plenárias, simpósios e oficinas de trabalho focaram-se os seguintes aspectos:

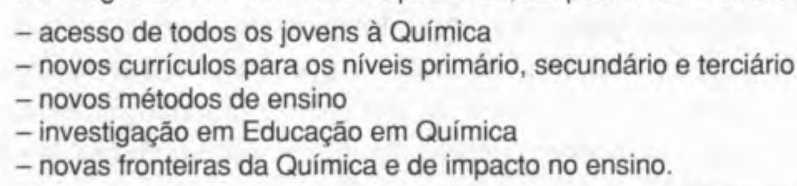

A conferência de abertura foi proferida pelo Prof. R.J.P. Williams que expôs sobre "Bringing inorganic chemistry to life». Na conferência de encerramento o professor W.S. Fyfe, Doutor Honoris causa pela Universidade de Lisboa, ilustrou de uma forma acutilante o tema «Education for Global responsability». Das restantes conferências plenárias salientaram-se as de Susan Adamson, ligada ao Science Education Group da Universidade de York que abordou o tema "Novas perspectivas de Educaçăo em Química» e a do Prof. H. Heikkinen, actual secretário do CEQ, sobre "A termodinâmica e a cinética da mudança em Educação em Química». De referir ainda a dificuldade da escolha das quatro conferências em simultâneo no último dia de A.H. Johnstone, W. de Vos, L.E. Summerlin e B.W. Sholloum.

A conferência foi uma ocasião para desenvolver e compartilhar projectos educacionais a nivel internacional. Com início na manhấ do primeiro dia numa "workshop" internacional, sob a responsabilidade dos Prof. H. Heikkinen e M. " Elisa M. Pestana, produziu-se uma unidade de ensino sobre "Água"; os participantes levaram a 1. ${ }^{a}$ versăo da unidade para os seus países para a traduzirem, aplicarem e adaptarem no programa de desenvolvimento curricular IUPAC - Unesco, iniciado em 1989 em Berkeley. Numa outra "workshop" foram apresentados dois dos projectos de desenvolvimento curricular em curso com uma dimensão europeia. Outro ponto alto correspondeu aos 20 simpósios e 34 oficinas de trabalho, preparados ao longo de vários meses, e nos quais se discutia um assunto em profundidade durante cerca de duas horas, podendo prolongar-se a discussão no caso dos participantes o entenderem. Houve também ocasião para apresentar e discutir inúmeros trabalhos sob a forma de comunicaçăo em cartaz.

Em paralelo organizaram-se pequenas reunióes ad -hoc, entre as quais sobre as Divisôes de Educação das Sociedades de Química e sobre as Associaçốes de Professores de Ciência, bem como da Newsletter, veículo de comunicação do Comité de Ensino da Química (CEQ) da IUPAC, publicado duas vezes por ano, de que apareceu uma versão em português durante cerca de quatro anos.

Referências

(1) Pereira, M.P. (1980). Conferência Internacional sobre Educaçấo em Quimica. - Tema: O ensino da Quimica - interacçăo dos níveis secundário e terciário. Boletim da SPQ, Ano 3. Série II, n. ${ }^{2} 3,40-43$.

(2) Gil, V.S. (1982), 6th International Conference on Chemical Education, - Tema: Teaching chemistry in a diverse world. Boletim da SPQ, Ano 5, Série II, n. ${ }^{2} 9$, $13-15$. 


\section{Convite à Relexão ...}

\section{Aprender: trazer à luz - mergulhar no escuro}

Kreuzer : Viver é, pois, uma aventura. Correm-se riscos para dispor de novas oportunidades. Que significa então «aprender»? Significará também expor doutrinas? Esboçar dogmas, doutrinas, teorias, hipóteses, para que sejam testadas no mundo?

Lorenz : Nós entendemos o título «Viver é aprender» de uma forma conceptual muito ampla: a aquisição de informações. E a aprendizagem de um animal, através do conditioning (condicionamento), da adaptação, é evidente algo completamente diferente da aprendizagem do experimentador, que propõe uma hipótese mais ou menos engenhosa, para ser testada. Isto tem a ver com a questão da indução, que já paira entre nós. Talvez voltemos a ela mais tarde...

Kreuzer : Penso que já lá estamos...

Lorenz : Julgo que não estamos assim tão distantes uns dos outros. Parece-me que determinados conhecimentos vão amadurecendo inconscientemente, precisamente porque os indivíduos pesantes têm tanto em comum entre si. Os conhecimentos novos desenvolvem-se à semelhança de fungos, subterraneamente, e então surge aqui, e ali, e mais além um cogumelo.

Popper : Existem dois tipos totalmente distintos de aprendizagem. Uma é a aventura, o aprender algo de novo, e a outra, é o empenhamento, o esforço de modo a, por assim dizer, desterrar algo, que se aprendeu, para o subconsciente. $\mathrm{Na}$ condução aprende-se a esquecer aquilo que se aprendeu e a prestar atenção à estrada, e em seguida só se presta atenção à estrada e o resto é automático. Para se tocar piano, de início é extremamente difícil coordenar os dedos com as notas, já que se está a aprender algo de novo. Mas depois, quando já se tiver aprendido o que era novo, procuramos dedicar-nos apenas ao essencial: à ideia do compositor.

Lorenz : Certo.

Popper : Existem, portanto, dois estádios completamente distintos da aprendizagem: o primeiro é a aprendizagem aventurosa, a aprendizagem do investigador, do descobridor, o outro, é o saber de cor - fora com ele, expulsêmo-lo para o subconsciente! A psicologia da aprendi- zagem considera, lamentavelmente, esta segunda espécie, insignificante, da aprendizagem como sendo a única: a aprendiagem pela repetição. $\mathrm{E}$ então-e agora estou a responder-te-sucede que toda a teoria da indução se erige com base neste erro da psicologia da aprendizagem. A repetição não desempenha qualquer papel no descobrir, apenas desempenha um papel no «esquecer». A repetição serve para nós automatizarmos algo, para que isso deixe de nos sobrecarregar, para que não tenhamos de prestar-lhe mais atenção. Existe uma enorme diferença entre a aprendizagem através do ensaio e do erro, que é sempre uma aventura, e a aprendizagem através da repetição, que nunca conduz a nada de novo, mas que apenas faz «esquecer» o aprendido, ou seja, que o impele para o subconsciente.

Lorenz : Eu diria que ela retém, que fixa... sim, concordo plenamente. No que se refere à experimentação, diga-se que todo o processo de adaptação do acontecimento da vida começa com a experiência. A aprendizagem pela repetição, como tu lhe chamas, é, pelo contrário, um processo de armazenamento de informações. O saber adquirido é remetido para o subconsciente, a fim de aliviar o espírito experimentador, mas no entanto ficamos dependentes dele, já que este saber mecanizado desviado para o subconsciente é o pressuposto da liberdade de que fazemos uso «superior». Toda a experiência consiste em estruturas, e toda a estrutura adquire capacidades para suportar pelo preço do sacrifício de um certo grau de liberdade. Um verme pode enroscar-se onde quiser, mas nós só nos conseguimos dobrar onde as articulações o permitem; no entanto, - podemos estar de pé e o verme não. Nas ocorrências intelęctuais superiores, as funções mecanizadas desempenham um papel muito importante como pressupostos do livre pensamento e da percepção figurativa.

Popper: Por exemplo, a tabuada como pressuposto da aritmética.

Lorenz : A tabuada é um pressuposto.

Popper: No entanto, não podemos dizer que aprendemos a tabuada por indução. Trata-se efectivamente de um equívoco...

K. Popper e K. Lorenz, «O Futuro está Aberto» 
